\title{
Assessment of the inter-lap stability and relationship between the race time and start, clean swim, turn and finish variables in elite male junior swimmers' $200 \mathrm{~m}$ freestyle
}

Jorge E Morais, Tiago M Barbosa, Pedro Forte, João N Pinto \& Daniel A Marinho

To cite this article: Jorge E Morais, Tiago M Barbosa, Pedro Forte, João N Pinto \& Daniel A Marinho (2021): Assessment of the inter-lap stability and relationship between the race time and start, clean swim, turn and finish variables in elite male junior swimmers' $200 \mathrm{~m}$ freestyle, Sports Biomechanics, DOI: 10.1080/14763141.2021.1952298

To link to this article: https://doi.org/10.1080/14763141.2021.1952298

\section{置 Published online: 26 Jul 2021.}

Submit your article to this journal ¿

Q View related articles $\longleftarrow$

View Crossmark data ־ 


\title{
Assessment of the inter-lap stability and relationship between the race time and start, clean swim, turn and finish variables in elite male junior swimmers' $200 \mathrm{~m}$ freestyle
}

\author{
Jorge E Morais $\mathbb{( D}^{\mathrm{a}, \mathrm{b}}$, Tiago M Barbosa $\mathbb{D}^{\mathrm{a}, \mathrm{b}}$, Pedro Forte $\mathbb{D}^{\mathrm{a}, \mathrm{b}, \mathrm{c}}$, João N Pinto \\ and Daniel A Marinho (iD ${ }^{\mathrm{b}, \mathrm{d}}$ \\ aDepartment of Sport Sciences, Polytechnic Institute of Bragança, Bragança, Portugal; ${ }^{b}$ Research Centre in \\ Sports, Health and Human Development (CIDESD), University of Beira Interior, Covilhã, Portugal; \\ 'Department of Sport Sciences and Physical Education, Higher Institute of Educational Sciences of the \\ Douro, Penafiel, Portugal; ${ }^{d}$ Department of Sport Sciences, University of Beira Interior, Covilhã, Portugal
}

\begin{abstract}
The aims of this study were to: (1) assess the stability (mean and normative) of the lap performance, and a set of clean swim and turn variables of junior male swimmers in the $200 \mathrm{~m}$ freestyle, and; (2) verify the relationship between the start, clean swim, turn, and finish phases in the $200 \mathrm{~m}$ freestyle. Seventy-six individual races in the $200 \mathrm{~m}$ freestyle at the 2019 long-course LEN European Junior Championships were analysed. Start, clean swim, turn, and finish variables were assessed. The lap performance showed a significant variance. The highest variation was verified between the first and third lap (Coefficient of Variation $=7.37 \%$ ). The clean swim and the total turn also presented a significant variance. Normative stability indicated a moderate to very-high stability for all variables. All phases of the race had significant correlations with the final race time ( $p<0.001)$. The total turn (i.e., the total time spent to perform the turn), specifically turn \#3, showed the largest correlation with the total race performance. The significant correlation between all phases of the race and the final race time indicates that coaches and swimmers should customise the swimmers' preparation and race strategy at major international competitions, based on the individual characteristics of each swimmer.
\end{abstract}

\section{KEYWORDS}

Swimming; race; stroke mechanics; variance

\section{Introduction}

The increased competition at major sports events led swimmers, coaches, support staff and researchers to better understand key areas of improvement for race success (Allen et al., 2015). Analysing elite athletes' performance at major events provides deep insights on how younger counterparts can enhance their performance. This can be achieved by breaking down the event into partial performances in each phase of the race (i.e., start, clean swim, turns, and finish) (Morais et al., 2019; Veiga \& Roig, 2016). The start is defined as the time spent between the starting signal and reaching the $15 \mathrm{~m}$ mark (Morais et al., 2019). The clean swim is the time spent travelling the $30 \mathrm{~m}$ in the middle of a long 
course swimming pool, and the turn is delimited as the time between the last $5 \mathrm{~m}$ of a lap and the first $15 \mathrm{~m}$ of the next one (Morais et al., 2020). The finish is considered as the last $5 \mathrm{~m}$ of the race (Suito et al., 2015).

Literature reports several studies on race analysis of elite swimmers at major competitions (Morais et al., 2020; Simbaña-Escobar et al., 2018). There are studies focused on specific phases of the race such as the start (Burkett et al., 2010; Peterson Silveira et al., 2018), the swim pace (Arellano, Brown, Cappaert \& Nelson, 1994; Simbaña-Escobar et al., 2018), turns (Mason et al., 2015; Veiga \& Roig, 2016), and finish (Marinho et al., 2020; Suito et al., 2015), or in the combination of some of these phases (Marinho et al., 2020; Morais et al., 2019).

Conversely, less is known about junior swimmers racing at major events (e.g., Allen et al., 2015; Yustres et al., 2019). Recently, a review study suggested that information on different race phases is a topic to be explored (Gonjo \& Olstad, 2021). Breaking down the race into phases provides a deeper insight on the swimmer's biomechanical behaviour and the implementation of the race strategy (Marinho et al., 2020; Veiga \& Roig, 2016). Thus, one can argue that providing this age-group of swimmers' insights on their own performance at major events may yield a significant impact on their development programme and the chances of delivering top-performances in adulthood.

Stability assessment is an approach to understand the swimmer's variance in a given variable during a race (Figueiredo et al., 2013; Morais et al., 2020). The $200 \mathrm{~m}$ freestyle event raises interest among researchers and coaches because most successful middledistance swimmers in this event are able not only to reach faster speeds in each lap but also are able to keep that speed more constant and stable throughout the race than their sprinters counterparts (Robertson et al., 2009). Thus, the $200 \mathrm{~m}$ event can cater the interest of either sprinters or middle-distance swimmers. In elite swimming, it was shown that swimmers racing in these events presented a low stability, i.e., significant variance between laps (Simbaña-Escobar et al., 2018). Nonetheless, to the best of our knowledge there are no studies on elite junior counterparts racing the $200 \mathrm{~m}$ distance, or any other distances.

Therefore, the aims of this study were to: (1) assess the stability of the lap performance, and the stability of a set of clean swim and turn variables of elite junior male swimmers in the $200 \mathrm{~m}$ freestyle event, and; (2) verify the relationship between the start, clean swim, turn, and finish phases in the $200 \mathrm{~m}$ freestyle event. It was hypothesised that: (1) a low stability (i.e., significant variance) for the lap performance, clean swim and turn variables would be verified and; (2) the clean swim phase would present the strongest association with the $200 \mathrm{~m}$ freestyle performance.

\section{Methods}

\section{Participants}

The performances of all 76 male individual races in the $200 \mathrm{~m}$ freestyle event at the 2019 long course metre LEN European Junior Championships held in Kazan (Russia) were analysed. Performance reached on average $94.40 \pm 2.61 \%$ and $90.73 \pm 2.51 \%$ of the $200 \mathrm{~m}$ freestyle junior world record and world record, respectively. 


\section{Data collection}

The official race times, each $50 \mathrm{~m}$ split (lap performance) and block times were retrieved from the official competition website (http://ejc2019.microplustiming.com/ indexEJC2019_web.php). All video clips were provided in high-definition video and at a sampling frequency of $50 \mathrm{~Hz}$. The setup system delivered real-time multi-angle recordings (10 pan-tilt-zoom cameras, AXIS v5915, Lund, Sweden). In every race, each swimmer was recorded by one camera (i.e., one camera per lane). Two other fixed cameras (AXIS q1635, Lund, Sweden) recorded both ends of the swimming pool, enabling the analysis of the start and turns, and ensuring the calibration of the distances based on the pool's marks (i.e., $5 \mathrm{~m}, 15 \mathrm{~m}, 25 \mathrm{~m}, 35 \mathrm{~m}$ and $45 \mathrm{~m}$ marks). The start flashing lights were synchronised with the official timer and were visible by all cameras. The start flashing light was used as reference to set the time-stamp on the race analysis software (Morais et al., 2020). Each race analysis was performed based on time and distance variables (being each one analysed by two expert analysts). The Intra-Class Correlation Coefficient (ICC) was used to assess the agreement between the measures related to time $(\mathrm{ICC}=0.998)$, and distance $(\mathrm{ICC}=0.997)$.

\section{Start and finish}

The following start and finish variables were selected for analysis: (1) block time (the time lag between the starting signal and the instant swimmer's feet left the block); (2) flight time (the time lag between the instant the toes left the block and the hands get in the water); (3) entry time (the time lag between the starting signal and the instant hands get in the water); (4) entry distance (the distance between the starting head-wall and where the hands get in the water); (5) underwater time (the time lag between the instant hand get in the water, and the head breaking out the water surface); (6) underwater distance (the distance between where the hands get in the water and, the head breaking out the water surface); (7) underwater velocity (between the entry time and water break time); (8) water break time (the time lag between the starting signal and the head breaking out the water surface); (9) break distance (the distance between the starting head-wall and the head water break); (10) $15 \mathrm{~m}$ time (the time lag between the starting signal and swimmer's head reaching the $15 \mathrm{~m}$ mark, this was selected as the main start outcome) (Morais et al., 2019). The finish was considered as the last $5 \mathrm{~m}$ (Suito et al., 2015). The finish time and speed started to be measured when the swimmer's head reached the $45^{\text {th }}$ metre mark and stopped when the swimmer's hand touched the end wall. Therefore, a speed correction was made based on the time that the swimmer's head would take to complete the remaining distance (Thompson et al., 2000).

\section{Clean swim}

All the clean swim variables were measured in the intermediate $30 \mathrm{~m}$ of the swimming pool (i.e., from the $15^{\text {th }}$ metre to the $45^{\text {th }}$ metre). The following variables were selected for analysis: (1) the clean swim speed (in $\mathrm{m} / \mathrm{s}$ ); (2) the stroke frequency (SF, in $\mathrm{Hz}$ ); (3) the stroke length (SL, in $\mathrm{m}$ ), and; (iv) the stroke index (SI, in $\mathrm{m}^{2} / \mathrm{s}$ ). The clean swim speed was calculated as $\mathrm{v}=\mathrm{d} / \mathrm{t}$, where $\mathrm{d}$ is the distance (in $\mathrm{m}$ ) and $\mathrm{t}$ is the time (in 
seconds). The SF was obtained by computing the period of the time spent to complete a full stroke cycle. This was analysed between the $15^{\text {th }}$ metre and $45^{\text {th }}$ metre (only full stroke cycles were considered, and the average was used for analysis). The SL was calculated as SL $=$ v/SF (Craig \& Pendergast, 1979), and the SI as SI $=\mathrm{v} \cdot \mathrm{SL}$ (Costill et al., 1985).

\section{Turning parameters}

The following variables were selected for analysis: (1) the $5 \mathrm{~m}$-in (the time lag between the head reaching the $45 \mathrm{~m}$ mark and the feet touching the wall-retrieved by the official split time); (2) water break time (the time lag between the touch on the wall and the head breaking out the water surface); (3) water break distance (the distance between the wall and the head breaking out the water surface); (4) underwater speed (between the touch on the wall and the head breaking out the water surface); (5) $15 \mathrm{~m}$-out (the time lag between the touch on the wall and reaching the $15 \mathrm{~m}$ mark), and; (6) the total turn (the time lag between reaching the $45 \mathrm{~m}$ mark and the $15 \mathrm{~m}$ mark of the following split). The total turn time was chosen as the main turn outcome (Morais et al., 2020).

\section{Statistical analysis}

The Kolmogorov-Smirnov and Levene tests were used to assess the normality and homoscedasticity assumptions, respectively, for all variables. The mean \pm one standard deviation (SD) was computed for all variables.

The swimmers' stability was assessed based on: (1) mean stability, and; (2) normative stability (Costa et al., 2011). Mean stability refers to the persistence of the magnitude of change over the race of a given variable. This was assessed by the ANOVA repeated measures (i.e., inter-lap variance), followed by the Bonferroni post-hoc test to verify significant differences between each pairwise $(\mathrm{p}<0.05)$. The effect size index (eta square $-\eta^{2}$ ) was computed and interpreted as: (1) without effect if $0<\eta^{2} \leq 0.04$; (2) minimum if $0.04<\eta^{2} \leq 0.25$; (3) moderate if $0.25<\eta^{2} \leq 0.64$ and; (4) strong if $\eta^{2}>0.64$ (Ferguson, 2009). The coefficient of variation (CV, in \%) was calculated for each pairwise. Cohen's $\mathrm{d}$ was selected as standardised effect size for each pairwise, and interpreted as: (1) small effect size $0 \leq|\mathrm{d}| \leq 0.2 ;(2)$ medium effect size if $0.2<|\mathrm{d}| \leq 0.5$ and; (3) large effect size if $|\mathrm{d}|>$ 0.5 (Cohen, 1988).

The normative stability focuses on the stability of inter-individual differences in intra-individual changes. It refers to the maintenance of the relative position of the swimmers within a group assessed over the race. This was assessed with the IntraClass Correlation Coefficient (ICC) between each pairwise. As a rule of thumb, it was defined that the stability was: (1) low if $\mathrm{r}<0.30$; (2) moderate if $0.30 \leq \mathrm{r}<0.60$; (3) high if $r \geq 0.60$ (Malina, 2001). To assess the association between the $200 \mathrm{~m}$ performance and remaining variables the Pearson's correlation coefficient $(p<0.05)$ was computed. As rule of thumb, for qualitative and effect size assessments the correlation/ relationship was defined as: (1) without effect if $0<\mathrm{r} \leq 0.20$; (2) minimum if $0.20<\mathrm{r} \leq 0.50$; (3) moderate if $0.50<\mathrm{r} \leq 0.80$ and; (4) strong if $\mathrm{r}>0.80$ (Ferguson, 2009). 


\section{Results}

\section{Start and finish}

Table 1 presents the descriptive statistics for start and finish variables. Swimmers took $6.28 \pm 0.26 \mathrm{~s}$ to achieve the $15 \mathrm{~m}$ mark (start main outcome), and $2.85 \pm 0.23 \mathrm{~s}$ during the last $5 \mathrm{~m}$ of the race (finish). The start accounted for $5.58 \pm 0.17 \%$ of the total race time, the clean swim $70.14 \pm 1.81 \%$, the turns $32.92 \pm 1.09 \%$, and the finish $2.53 \pm 0.18 \%$ (Table 1 ).

\section{Lap performance and clean swim}

Table 1 presents the swimmers' mean stability for the lap performance and clean swim variables during the $200 \mathrm{~m}$ race. The lap performance showed a significant variance (moderate effect size) $\left(\mathrm{F}=562.03, \mathrm{p}<0.001, \eta^{2}=0.62\right)$ (Table 1). The largest difference was observed between lap \#1 and lap \#3 (CV = 7.37\%, $\mathrm{d}=3.66, \mathrm{p}<0.05)$ (Figure 1 and Table 2$)$. The clean swim time $\left(\mathrm{F}=248.92, \mathrm{p}<0.001, \eta^{2}=0.54\right)$, and consequently the swim speed $\left(\mathrm{F}=282.24, \mathrm{p}<0.001, \eta^{2}=0.57\right)$, presented a significant variance (moderate effect size) (Table 1). The largest difference was observed between lap \#1 and lap \#4 (clean swim time: $\mathrm{CV}=6.33 \%, \mathrm{~d}=2.51, \mathrm{p}<0.05$; swim speed: $\mathrm{CV}=6.11 \%, \mathrm{~d}=2.47, \mathrm{p}<0.05$ ) (Figure 1 and Table 2). Normative stability is presented in Table 2. Lap performance

Table 1. Descriptive statistics for the $200 \mathrm{~m}$ performance, start, and finish variables evaluated. It presents the ANOVA repeated-measures analysis for the performance (split time), pace and turn variables.

\begin{tabular}{|c|c|c|c|c|c|}
\hline & \multirow{2}{*}{$\begin{array}{l}\text { Descriptive } \\
\text { Mean } \pm 1 S D\end{array}$} & \multirow{2}{*}{$\frac{\text { Relative contribution }}{(\%)}$} & \multicolumn{3}{|c|}{ ANOVA repeated-measures } \\
\hline & & & F-ratio & $P$ value & $\eta^{2}$ \\
\hline Performance $[\mathrm{s}]$ & $112.51 \pm 3.18$ & & & & \\
\hline Lap performance $[\mathrm{s}]$ & & & 562.30 & $<0.001$ & 0.62 \\
\hline \multicolumn{6}{|l|}{ Start } \\
\hline $15 \mathrm{~m}$ mark time $[\mathrm{s}]$ & $6.28 \pm 0.26$ & $5.58 \pm 0.17$ & & & \\
\hline Block time $[\mathrm{s}]$ & $0.69 \pm 0.04$ & & & & \\
\hline Entry time $[\mathrm{s}]$ & $0.92 \pm 0.06$ & & & & \\
\hline Flight time [s] & $0.25 \pm 0.14$ & & & & \\
\hline Entry distance $[\mathrm{m}]$ & $3.07 \pm 0.28$ & & & & \\
\hline Underwater time $[\mathrm{s}]$ & $3.41 \pm 0.56$ & & & & \\
\hline Underwater distance [m] & $7.00 \pm 2.37$ & & & & \\
\hline Underwater speed [m/s] & $2.05 \pm 0.57$ & & & & \\
\hline Water breakout time [s] & $4.33 \pm 0.57$ & & & & \\
\hline Water breakout distance [m] & $10.08 \pm 2.39$ & & & & \\
\hline \multicolumn{6}{|l|}{ Clean swim } \\
\hline Intermediate $30 \mathrm{~m}$ time $[\mathrm{s}]$ & & $70.14 \pm 1.81$ & 248.92 & $<0.001$ & 0.54 \\
\hline Swim speed [m/s] & & & 282.24 & $<0.001$ & 0.57 \\
\hline Stroke frequency $[\mathrm{Hz}]$ & & & 58.75 & $<0.001$ & 0.10 \\
\hline Stroke length [m] & & & 126.11 & $<0.001$ & 0.17 \\
\hline Stroke index $\left[\mathrm{m}^{2} / \mathrm{s}\right]$ & & & 312.51 & $<0.001$ & 0.34 \\
\hline \multicolumn{6}{|l|}{ Turn } \\
\hline Total turn [s] & & $32.92 \pm 1.09$ & 104.67 & $<0.001$ & 0.18 \\
\hline $5 \mathrm{~m}$-in [s] & & & 117.12 & $<0.001$ & 0.27 \\
\hline Water breakout time [s] & & & 11.61 & $<0.001$ & 0.03 \\
\hline Water breakout distance [m] & & & 39.15 & $<0.001$ & 0.08 \\
\hline Underwater speed $[\mathrm{m} / \mathrm{s}]$ & & & 41.33 & $<0.001$ & 0.12 \\
\hline $15 \mathrm{~m}$-out $[\mathrm{s}]$ & & & 37.11 & $<0.001$ & 0.08 \\
\hline \multicolumn{6}{|l|}{ Finish } \\
\hline $5 \mathrm{~m}$ time $[\mathrm{s}]$ & $2.85 \pm 0.23$ & $2.53 \pm 0.18$ & & & \\
\hline $5 \mathrm{~m}$ swim speed $[\mathrm{m} / \mathrm{s}]$ & $1.63 \pm 0.15$ & & & & \\
\hline
\end{tabular}

Performance-200 $\mathrm{m}$ final race time; $\eta^{2-}$ eta square (effect size index). 

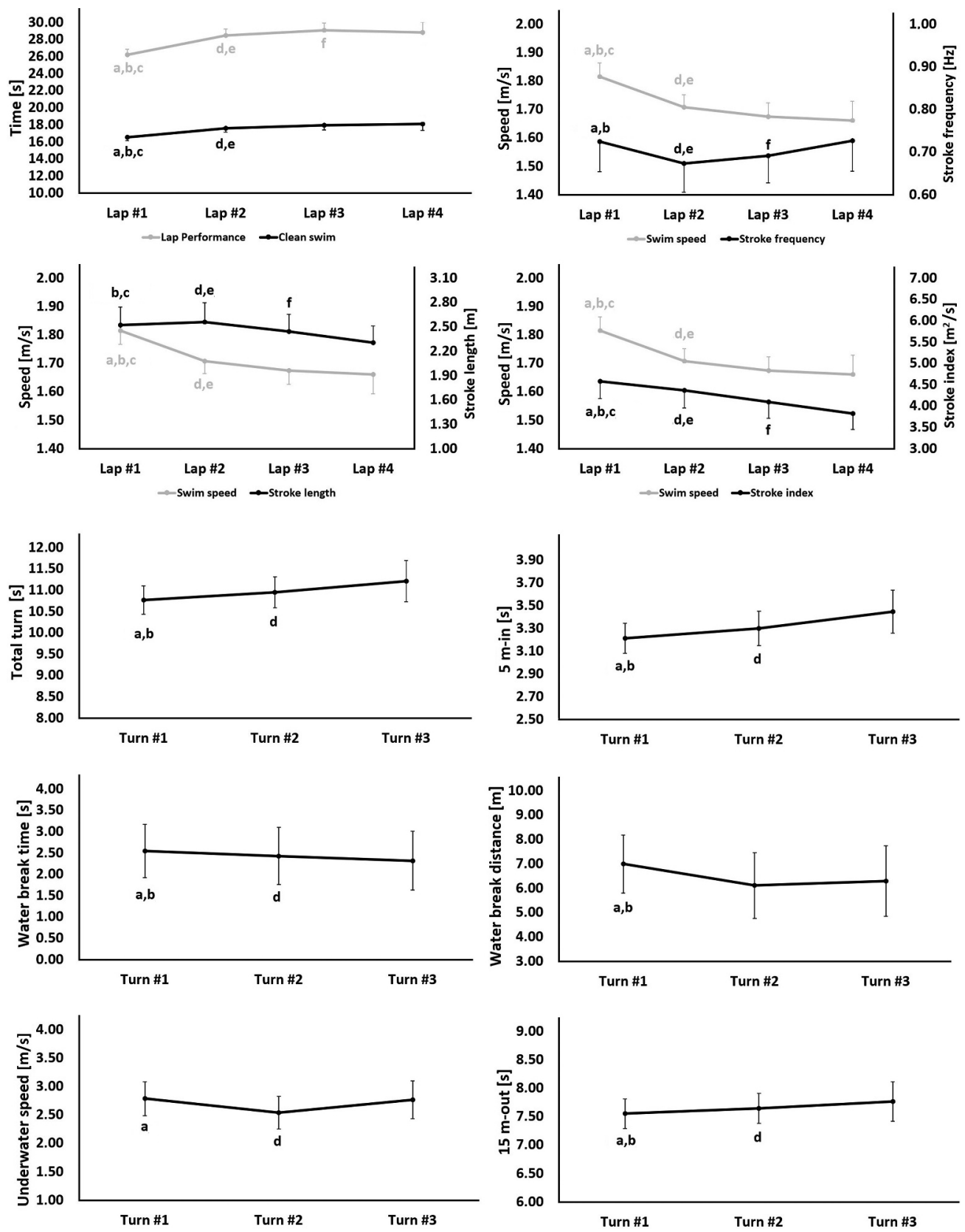

Figure 1. Mean stability of the $200 \mathrm{~m}$ freestyle performance, pace (during the intermediate $30 \mathrm{~m}$ ), and turn variables. Performance-200 m freestyle race. Significant differences $(p<0.05)$ between laps and turns: $\mathrm{a}-\# 1$ vs \#2; b-\#1 vs \#3; c-\#1 vs \#4; $\mathrm{d}-\# 2$ vs \#3; e-\#2 vs \#4; $\mathrm{f}-\# 3$ vs \#4.

showed a high stability, and the variables related to the clean swim showed a moderate to high normative stability. This indicates that swimmers tended to maintain their relative position within the group of swimmers analysed. 


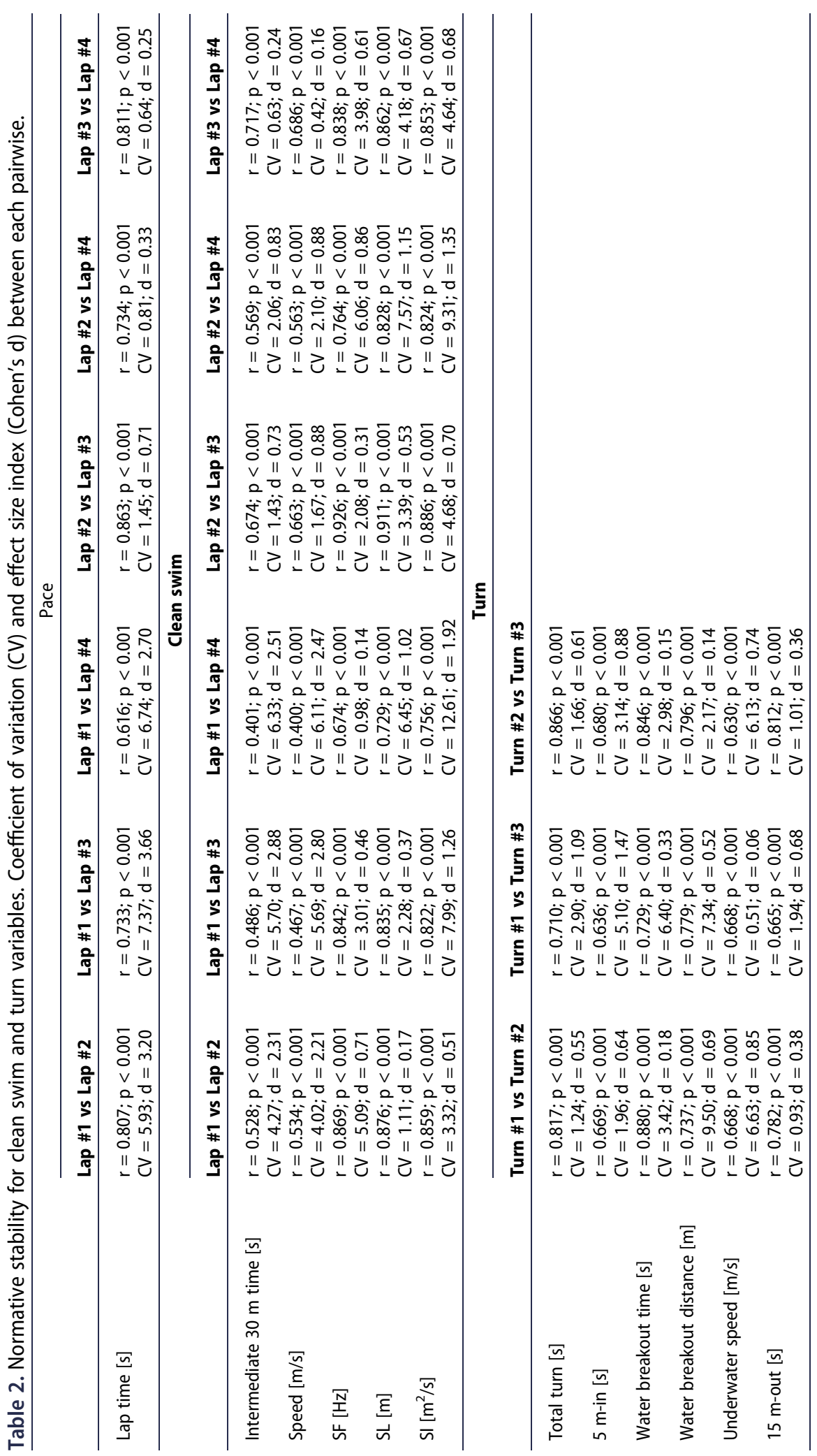




\section{Turn}

Table 1 presents the mean stability for the turn variables during the $200 \mathrm{~m}$ race. The total turn showed a significant variance (minimum effect size) $(\mathrm{F}=104.67, \mathrm{p}<0.001$, $\eta^{2}=0.18$ ) (Table 1). The highest difference was observed between turn \#1 and turn \#3 $(\mathrm{CV}=2.90 \%, \mathrm{~d}=1.09, \mathrm{p}<0.05)$ (Figure 1 and Table 2$)$. The $5 \mathrm{~m}$-in showed the highest and significant variance (moderate effect size) $\left(\mathrm{F}=117.12, \mathrm{p}<0.001, \eta^{2}=0.27\right)$ (Table 1$)$. The highest difference was observed between turn \#1 and turn \#3 (CV = 5.10\%, $d=1.47$, $\mathrm{p}<0.05$ ) (Figure 1 and Table 2). Normative stability is presented in Table 2. The variables related to the turn showed a high normative stability, i.e., swimmers tended to maintain their relative position within the group of swimmers analysed.

\section{Relationship between 200 m performance and remaining variables}

Table 3 presents the Pearson's correlation coefficient between the $200 \mathrm{~m}$ performance with the start, clean swim, turn and finish variables. The $200 \mathrm{~m}$ performance presented the strongest correlation $(r=0.919, \mathrm{p}<0.001)$ with turn \#3. Overall, the final race time showed a significant and moderate to strong associations with the clean swim, and a significant and moderate association with the $15 \mathrm{~m}$ mark time (start main outcome) (Table 3).

\section{Discussion and Implications}

The aims of this study were to: (1) assess the stability of the the lap performance, and a set of clean swim performance and turn variables of elite junior male swimmers during a $200 \mathrm{~m}$ freestyle race, and; (2) verify the association between the start, clean swim, turn, and finish phases and the $200 \mathrm{~m}$ freestyle final race time. A significant and moderate variance was verified in the lap performance (wall-to-wall time) (with a high normative stability). The clean swim variables (during the intermediate $30 \mathrm{~m}$ ) presented

Table 3. Pearson's correlation coefficient between the $200 \mathrm{~m}$ performance and the start, clean swim, turn and finish variables.

\begin{tabular}{lcc}
\hline & $\mathrm{r}$ & $\mathrm{p}$ \\
\hline Start & & \\
15 m mark time & 0.684 & $<0.001$ \\
Clean swim & & \\
Lap \#1 & 0.607 & $<0.001$ \\
Lap \#2 & 0.797 & $<0.001$ \\
Lap \#3 & 0.876 & $<0.001$ \\
Lap \#4 & 0.855 & $<0.001$ \\
Turn & & \\
Total turn \#1 & 0.833 & $<0.001$ \\
Total turn \#2 & 0.904 & $<0.001$ \\
Total turn \#3 & 0.919 & $<0.001$ \\
Finish & & \\
Finish time & 0.523 & $<0.001$ \\
Finish speed & -0.416 & $<0.001$ \\
\hline Clean swim-refers to the 30 m stretch in the middle of in each split.
\end{tabular}

Clean swim—refers to the $30 \mathrm{~m}$ stretch in the middle of in each split. 
a significant and minimum-moderate variance (with a moderate to high normative stability). The total turn showed a minimum but significant variance (with a high normative stability). All variables selected were significantly correlated with the final race time having minimum to strong effect sizes.

\section{Lap, clean swim, and turn stability}

Swimmers exhibit a significant and moderate variance (i.e., inter-lap variance) in the lap and clean swim performance. Nonetheless, it was possible to note that this effect was higher in the lap performance (wall-to-wall) than in the clean swim $(30 \mathrm{~m}$ in the middle of the pool) performance. This is highlighted by the coefficient of variation, which is lower in the clean swim. Moreover, the trend of the lap performance did not match the clean swim performance, notably in the second half of the race (lap \#3 and lap \#4). In other words, lap performance significantly improved (i.e., less time to cover the distance), and clean swim performance declined (i.e., more time to cover the distance, but not significant). This leads to the argument that lap performance is not representative of clean swim performance. Indeed, the latter (measured in the mid-section of the pool) discards the start and turn effects (which are included in the lap time) (Morais et al., 2020; Veiga \& Roig, 2016).

Most 200 m elite freestylers, across a range of competitive levels, select an even pacing (i.e., perform a fast start, and afterwards a relatively even pace) (Huot-Marchand et al., 2005). However, there are other elite swimmers that choose a positive pacing (i.e., a significant increase in time, and a consequent decrease in speed, from split to split) (Simbaña-Escobar et al., 2018; Veiga \& Roig, 2016). In the case of junior elite swimmers, our data showed a positive pacing for the lap performance but with a significant fast last lap in comparison to the previous lap. Interestingly, when analysing the clean swim it was noted that the swimmers exhibit a positive pacing all the way from the first to the last lap with significant differences between laps (except between lap \#3 and lap \#4). The last lap was raced at an average speed of 1.74 and $1.66 \mathrm{~m} / \mathrm{s}$ if computed based on the lap time and clean swim, respectively. This confirms that pace analysis based on official lap times may present a bias in comparison to clean swim. Indeed, similar results have been observed in elite swimmers racing the same $200 \mathrm{~m}$ distance at the 2013 World Championships (Veiga \& Roig, 2016). Turns and start should be analysed separately to better understand the implementation of the race strategy by each swimmer.

All turning variables showed significant variance but ranging between without effect to moderate effect. The turn main outcome (i.e., total turn, that comprises the $5 \mathrm{~m}$-in and $15 \mathrm{~m}$-out variables) showed a significant variance with a moderate effect size and noting a significant increase between laps. The $5 \mathrm{~m}$-in (approach to the turning wall) presented a larger inter-lap difference ( $\mathrm{CV}$ and $\mathrm{d}$-effect size) in all pairwise in comparison to the 15 m-out. Thus, it can be suggested that the approach to the turning wall was the main factor responsible for the trend observed by the total turn (i.e., performance decrease). This could be related to the decrease in the swimmer's energetic profile during the clean swim at the end of each lap (Pyne \& Sharp, 2014). Swimmers significantly increased their $5 \mathrm{~m}$-in time during the race. The $5 \mathrm{~m}$-in can be considered as the transition from the clean swim phase to the beginning of the turn (Tor et al., 2014). Therefore, in the last $5 \mathrm{~m}$ of the pool's length (i.e., turn $5 \mathrm{~m}$-in) swimmers may present fatigue indexes. 
A study reported the underwater profile of elite swimmers racing at the 2013 World Championships (Veiga \& Roig, 2016). The authors verified that water break distance of elite male swimmers became shorter over the race (turn \#1: $7.35 \mathrm{~m}$; turn \#2: $7.21 \mathrm{~m}$; turn \#3: $6.69 \mathrm{~m}$ ) (Veiga \& Roig, 2016). Our data showed a similar trend, except for the last turn. That is, junior swimmers increased slightly (but not significantly) the water break distance in the last turn (turn \#3) in comparison to the previous one (turn \#2). It can be suggested that junior swimmers try to save some energy during the underwater phase, that is going to be used in the all-out effort in the clean swim phase right before finishing the race.

\section{Relationship between 200 m performance and remaining variables}

The $200 \mathrm{~m}$ performance presented a significant correlation with all selected variables (i.e., start, clean swim, turn and finish). Swimming research historically puts a lot of focus on the clean swim phase because this phase is highly associated to the final race time (Morais et al., 2019; Robertson et al., 2009). Our data showed that all clean swim variables (i.e., lap \#1, lap \#2, lap \#3 and lap \#4) had a positive and significant relationship with the final race time. That is, more time to cover the intermediate $30 \mathrm{~m}$ (i.e., distance between the $15^{\text {th }}$ and $45^{\text {th }}$ metre) led to a higher final race time. From the four laps, the third lap was the one showing the strongest association with the final race time. In other words, less time spent in the third lap (clean swim) is related to shorter final race time. This was also noted in elite swimmers in the same distance and swim stroke (Robertson et al., 2009). Moreover, the fourth lap (clean swim phase) had an almost strong relationship with the final race time. Thus, the clean swim phase is indeed the main factor responsible for the final race time, with a particular emphasis on the third and fourth laps.

Regarding the start, studies can be found about kinematic and kinetic variables that can be improved to enhance the start (i.e., time at the $15 \mathrm{~m}$ mark) (Burkett et al., 2010; Tor et al., 2015; Vantorre et al., 2010). However, less studies related the start with the race performance (Cossor \& Mason, 2001; Morais et al., 2019). The start main outcome (15 m mark) had a positive and significant correlation (moderate) with the final race time. Swimmers taking more time to achieve the $15 \mathrm{~m}$ mark also took more time to complete the race. Studies noted that the faster swimmers achieving the $15 \mathrm{~m}$ mark also reached faster velocities at the beginning of the clean swim phase (Cossor \& Mason, 2001; Veiga \& Roig, 2017). This suggests faster starters are also able to keep such fast speed during the clean swimming. Indeed, our data showed that the first lap was the fastest, and this must be related to fast starts.

Literature presents fewer studies about the finish than the start and clean swim phases (Marinho et al., 2020; Suito et al., 2015). The finish is related to the ability of keeping or increasing the clean swim speed in the last $5 \mathrm{~m}$ of the race (Arellano et al., 1994). A significant and moderate correlation was found between the final race time and the finish time. Junior swimmers performed the clean swim of the last lap at $1.66 \pm 0.07 \mathrm{~m} / \mathrm{s}$ and the finish (i.e., last $5 \mathrm{~m}$ of the race) at $1.63 \pm 0.15 \mathrm{~m} / \mathrm{s}$, which showed to be significantly different (mean difference $=-0.039,95 \mathrm{CI}$ : -0.071 to $-0.008, \mathrm{t}=-2.503$, $\mathrm{p}=0.015, \mathrm{~d}=0.26$ ). This phenomenon can be related mainly to the swimmer's energetic profile (i.e., fatigue). It was shown that swimmers racing the $200 \mathrm{~m}$ freestyle event yielded the highest energy expenditures in the first and last lap (non-significant differences 
between such laps) (Figueiredo et al., 2011). Moreover, Campos et al. (2017) noted that the total anaerobic contribution is significantly higher in this race distance. This suggests that swimmers who can save some energy (mainly anaerobic pathways) until the end of the race may be able to decrease less the swim speed.

The assessment of turns is becoming of paramount importance for swimming community (Marinho et al., 2020; Veiga \& Roig, 2016). Our data shows that fast turns are significantly correlated to the final race time. In other words, swimmers that spent a higher amount of time turning (total turn: $5 \mathrm{~m}$-in and $15 \mathrm{~m}$-out) presented poorer final race times. This was notable in the last turn (highest and strongest correlation). As aforementioned, fatigue (energetic profile) can be responsible for the trend presented by total turn, i.e., poorer turning performance throughout the race. It was suggested that swimmers racing the $200 \mathrm{~m}$ events can optimise the total turn by increasing the underwater distance, and hence saving energy to the clean swim (Marinho et al., 2020). In the past, B. R. Mason and Cossor (2001) reported that faster swimmers in the clean swim phase at the 2000 Olympic Games were not the fastest turners. The authors suggested that clean swim performance does not necessarily reflect a similar skill in turning (B. R. Mason \& Cossor, 2001). More recently it was suggested that swimmers decrease the swim speed before performing a turn, suggesting that turns are a task-constraint that requires specific training (Simbaña-Escobar et al., 2018).

Swimmers always spent a considerable amount of time practicing the clean swim phase. These days, they are also focusing on the start, turn, and finish, especially those racing short or short middle-distance events (Marinho et al., 2020; Simbaña-Escobar et al., 2018). Improving the start, turn, or finish (or ideally all of them) can be of paramount importance on improving the final race time. The start and turn require meaningful tasks constraints due to its performance singularity. The finish phase (despite being like the clean swim phase regarding the stroke motion) also requires mechanical constraints to adjust the distance between the body and the wall (Gonjo \& Olstad, 2021). Thus, coaches and swimmers should be advised and encouraged to: (1) as the start (i.e., $15 \mathrm{~m}$ mark time) and turn were significantly correlated with the final race time a substantial amount of time should be dedicated to perform drills related to these phases of the race, and; (2): the base matrix of the strategy used by the swimmers was similar among them (normative stability finding). However, this should be adapted to the individual characteristics of each swimmer based on their strengths and handicaps in each phase of the race, and thus designing customised drills for each swimmer (mean stability finding).

It can be suggested to compare the effect between different groups (per example, between elite and sub-elite swimmers) to better understand which differ the fastest from the slowest swimmers in each part of the race. The main limitation of this study can be the potential effects of the distance between the cameras and the swimming pool, lens distortion, and the angle between each swimmer and the cameras. Studies concluded that the errors are negligible even when a single lens is used (B. Mason \& Formosa, 2011; Tor et al., 2012). Nonetheless, the videos analysed in the present study were recorded by realtime multi-angle cameras. The cameras followed the swimmers along the pool, ensuring the minimisation of potential effects. Moreover, the ICC between the two expert race analysts was assessed revealing a perfect agreement for time variables, and almost perfect for distances. 


\section{Conclusion}

It can be concluded that junior elite swimmers presented a significant variance in the lap performance, clean swim, and turn (with a high normative stability). Overall, the clean swim phase, turns, start, and finish were strongly correlated with the $200 \mathrm{~m}$ freestyle final race time. This highlights the need for coaches and swimmers to dedicate time on improving not only to the clean swim, but also the remainig phases of the race.

\section{Acknowledgments}

To LEN and Spiideo AB for providing the video clips. This project was supported by the National Funds through FCT - Portuguese Foundation for Science and Technology (UIDB/DTP/04045/2020).

\section{Disclosure statement}

No potential conflict of interest was reported by the author(s).

\section{ORCID}

Jorge E Morais (D) http://orcid.org/0000-0002-6885-0648

Tiago M Barbosa (D) http://orcid.org/0000-0001-7071-2116

Pedro Forte (D) http://orcid.org/0000-0003-0184-6780

Daniel A Marinho (D) http://orcid.org/0000-0003-2351-3047

\section{References}

Allen, S. V., Vandenbogaerde, T. J., Pyne, D. B., \& Hopkins, W. G. (2015). Predicting a nation's Olympic-qualifying swimmers. International Journal of Sports Physiology and Performance, 10 (4), 431-435. https://doi.org/10.1123/ijspp.2014-0314

Arellano, R., Brown, P., Cappaert, J., \& Nelson, R. (1994). Analysis of 50, 100 and $200 \mathrm{~m}$ freestyle swimmers at the 1992 Olympic games. Journal of Applied Biomechanics, 10(2), 189-199. https:// doi.org/10.1123/jab.10.2.189

Burkett, B., Mellifont, R., \& Mason, B. (2010). The influence of swimming start components for selected Olympic and Paralympic swimmers. Journal of Applied Biomechanics, 26(2), 134-141. https://doi.org/10.1123/jab.26.2.134

Campos, E. Z., Kalva-Filho, C. A., Gobbi, R. B., Barbieri, R. A., Almeida, N. P., \& Papoti, M. (2017). Anaerobic contribution determined in swimming distances: Relation with performance. Frontiers in Physiology, 8, Article 755. https://doi.org/10.3389/fphys.2017.00755

Cohen, J. (1988). Statistical power analysis for the behavioral sciences (2nd ed). Lawrence Earlbaum Associates.

Cossor, J. M., \& Mason, B. R. (2001). Swim start performances at the Sydney 2000 Olympic games. In J. Blackwell \& R. H. Sanders (Eds.), Proceedings of swim sessions: XIX international symposium on biomechanics in sports (pp. 70-74). International Society of Biomechanics in Sports.

Costa, M. J., Marinho, D. A., Bragada, J. A., Silva, A. J., \& Barbosa, T. M. (2011). Stability of elite freestyle performance from childhood to adulthood. Journal of Sports Sciences, 29(11), 1183-1189. https://doi.org/10.1080/02640414.2011.587196

Costill, D. L., Kovaleski, J., Porter, D., Kirwan, J., Fielding, R., \& King, D. (1985). Energy expenditure during front crawl swimming: Predicting success in middle-distance events. International Journal of Sports Medicine, 6(5), 266-270. https://doi.org/10.1055/s-2008-1025849 
Craig, A. B., \& Pendergast, D. R. (1979). Relationships of stroke rate, distance per stroke, and velocity in competitive swimming. Medicine and Science in Sports, 11, 278-283.

Ferguson, C. J. (2009). An effect size primer: A guide for clinicians and researchers. Professional Psychology: Research and Practice, 40(5), 532-538. https://doi.org/10.1037/a0015808

Figueiredo, P., Pendergast, D. R., Vilas-Boas, J. P., \& Fernandes, R. J. (2013). Interplay of biomechanical, energetic, coordinative, and muscular factors in a $200 \mathrm{~m}$ front crawl swim. BioMed Research International, 2013, 897232. https://doi.org/10.1155/2013/897232

Figueiredo, P., Zamparo, P., Sousa, A., Vilas-Boas, J. P., \& Fernandes, R. J. (2011). An energy balance of the $200 \mathrm{~m}$ front crawl race. European Journal of Applied Physiology, 111(5), 767-777. https://doi.org/10.1007/s00421-010-1696-z

Gonjo, T., \& Olstad, B. H. (2021). Race analysis in competitive swimming: A narrative review. International Journal of Environmental Research and Public Health, 18(1), article 69. https://doi. org/10.3390/ijerph18010069

Huot-Marchand, F., Nesi, X., Sidney, M., Alberty, M., \& Pelayo, P. (2005). Swimming: Variations of stroking parameters associated with $200 \mathrm{~m}$ competitive performance improvement in topstandard front crawl swimmers. Sports Biomechanics, 4(1), 89-100. https://doi.org/10.1080/ 14763140508522854

Malina, R. M. (2001). Adherence to physical activity from childhood to adulthood: A perspective from tracking studies. Quest, 53(3), 346-355. https://doi.org/10.1080/00336297.2001.10491751

Marinho, D. A., Barbosa, T. M., Neiva, H. P., Silva, A. J., \& Morais, J. E. (2020). Comparison of the start, turn and finish performance of elite swimmers in $100 \mathrm{~m}$ and $200 \mathrm{~m}$ races. Journal of Sports Science and Medicine, 19, 397-407.

Mason, B., \& Formosa, D. (2011). Competition analysis. In L. Seifert, D. Chollet, \& I. Mujika (Eds.), The world book of swimming: From science to performance (pp. 411-424). Nova Science Publishers.

Mason, B. R., \& Cossor, J. M. (2001). Swim turn performances at the Sydney 2000 Olympic Games. In J. Blackwell \& R. H. Sanders (Eds.), Proceedings of swim sessions: XIX international symposium on biomechanics in sports (pp. 65-69). San Francisco.

Mason, B. R., Sacilotto, G., Hazrati, P., \& Mackintosh, C. (2015). Characteristics of elite swim turn performances. In F. Colloud, M. Domalain, \& T. Monnet (Eds.), 33rd International Conference on Biomechanics in Sports (pp. 1090-1093). Poitiers.

Morais, J. E., Barbosa, T. M., Forte, P., Bragada, J. A., Castro, F. A. S., \& Marinho, D. A. (2020). Stability analysis and prediction of pacing in elite $1500 \mathrm{~m}$ freestyle male swimmers. Sports Biomechanics.

Morais, J. E., Marinho, D. A., Arellano, R., \& Barbosa, T. M. (2019). Start and turn performances of elite sprinters at the 2016 European Championships in swimming. Sports Biomechanics, 18(1), 100-114. https://doi.org/10.1080/14763141.2018.1435713

Peterson Silveira, R., Stergiou, P., Figueiredo, P., Castro, F., Katz, L., \& Stefanyshyn, D. J. (2018). Key determinants of time to $5 \mathrm{~m}$ in different ventral swimming start techniques. European Journal of Sport Science, 18(10), 1317-1326. https://doi.org/10.1080/17461391.2018.1486460

Pyne, D. B., \& Sharp, R. L. (2014). Physical and energy requirements of competitive swimming events. International Journal of Sport Nutrition \& Exercise Metabolism, 24(4), 351-359. https:// doi.org/10.1123/ijsnem.2014-0047

Robertson, E., Pyne, D., Hopkins, W., \& Anson, J. (2009). Analysis of lap times in international swimming competitions. Journal of Sports Sciences, 27(4), 387-395. https://doi.org/10.1080/ 02640410802641400

Simbaña-Escobar, D., Hellard, P., Pyne, D. B., \& Seifert, L. (2018). Functional role of movement and performance variability: Adaptation of front crawl swimmers to competitive swimming constraints. Journal of Applied Biomechanics, 34(1), 53-64. https://doi.org/10.1123/jab.20170022

Suito, H., Nunome, H., \& Ikegami, Y. (2015). Relationship between 100m race times and start, stroke, turn, finish phases at the freestyle japanese swimmers. In F. Colloud, M. Domalain, \& T. Monnet (Eds.), 33rd international conference on biomechanics in sports (pp. 1224-1227). Poitiers. 
Thompson, K. G., Haljand, R., \& MacLaren, D. P. (2000). An analysis of selected kinematic variables in national and elite male and female $100-\mathrm{m}$ and $200-\mathrm{m}$ breaststroke swimmers. Journal of Sports Sciences, 18(6), 421-431. https://doi.org/10.1080/02640410050074359

Tor, E., Ball, K., Pease, D., \& Hopkins, W. (2012). A comparison between single and multi-camera swimming race analysis systems. In E. J. Bradshaw, A. Burnett, \& P. A. Hume (Eds.), 30th annual conference of biomechanics in sports (pp. 188-191). Melbourne.

Tor, E., Pease, D. L., \& Ball, K. A. (2015). Key parameters of the swimming start and their relationship to start performance. Journal of Sports Sciences, 33(13), 1313-1321. https://doi. org/10.1080/02640414.2014.990486

Tor, E., Pease, D. L., Ball, K. A., \& Hopkins, W. G. (2014). Monitoring the effect of race-analysis parameters on performance in elite swimmers. International Journal of Sports Physiology and Performance, 9(4), 633-636. https://doi.org/10.1123/ijspp.2013-0205

Vantorre, J., Seifert, L., Fernandes, R. J., Vilas-Boas, J. P., \& Chollet, D. (2010). Kinematical profiling of the front crawl start. International Journal of Sports Medicine, 31(1), 16-21. https://doi.org/10.1055/s-0029-1241208

Veiga, S., \& Roig, A. (2016). Underwater and surface strategies of $200 \mathrm{~m}$ world level swimmers. Journal of Sports Sciences, 34(8), 766-771. https://doi.org/10.1080/02640414.2015.1069382

Veiga, S., \& Roig, A. (2017). Effect of the starting and turning performances on the subsequent swimming parameters of elite swimmers. Sports Biomechanics, 16(1), 34-44. https://doi.org/10. 1080/14763141.2016.1179782

Yustres, I., del Cerro, J. S., González-Mohíno, F., Peyrebrune, M., \& González-Ravé, J. M. (2019). Analysis of world championship swimmers using a performance progression model. Frontiers in Psychology, 10. https://doi.org/10.3389/fpsyg.2019.03078 